\title{
Perceptions of mothers about food allergy - A preliminary report
}

\author{
Endy P. Prawirohartono \\ Department of Child Health, Medical School University of Gadjah Mada, Sardjito Hospital, Jogja - Indonesial
}

\begin{abstract}
The impact of food allergy on child growth and development should be properly evaluated, although the prevalence of food allergy is low. Most mothers in Indonesia still practice food elimination if their children are suspected to suffer from food allergy. Types of food that are usually avoided are high-class protein sources such as egg, milk, beef and fish. These types of foods are important for maintaining growth and development during childhood. The aim of this study is to know the perceptions of mothers about food allergy, including its pathophysiology, clinical symptoms and signs, management, and types of foods as allergens. Among mostly 114 of medium to highly educated mothers, there were still wrong perceptions about food allergy. From 114 mothers, $48.2 \%$ of them believed that food allergy can not be inherited, egg causes furuncle $(54.3 \%)$, breast milk causes atopic eczema $(46.5 \%)$, and food allergy does not relate to respiratory symptoms. There was a relationship between these perceptions and mothers' educational level. Skin manifestations were most popular among mothers, whereas only $37.7 \%$ of mothers believed that food allergy can causes respiratory symptoms. Egg, shrimp, fish, and shellfish were types of animal foods which were popular, whereas peanut, soy, banana, rice and vegetables were recognized as the major causes of food allergy among non animal products. [Paediatr Indones 2001; 41:180-184]
\end{abstract}

Keywords: mothers' perceptions, food allergy

THE PREVALENCE OF FOOD ALLERGY IS LOW, ABOUT $1.4 \%(0.5 \%$ to $3.8 \%)$ in young children ${ }^{1}$, but its impacts on child growth and development should be properly evaluated. Most of mothers in Indonesia still practice food elimination if their children are suspected from having food allergy. In general, high-class animal proteins, such as egg, milk, beef, and fish are commonly eliminated. These kinds of foods are important as the source of nutrients for maintaining growth and development during childhood. The problem arises when mothers

Correspondence: Endy P Prawirohartono, M.D., Department of Child Health, Medical School, Gadjah Mada University, Jalan Kesehatan No, 1, Yogyakjarta, Indonesia improperly eliminate because of wrong perception about food allergy. These wrong perceptions are not merely from mothers themselves, but some health workers have given wrong advice and given 'a long list of foods' those should be avoided by the children.

Food allergy and food intolerance are changeably used. Double blind placebo-controlled food challenge as a standard diagnostic test of food allergy has not been routinely performed in clinical setting. Therefore, diagnose of food allergy is merely based on the report of parents and the "intuition' of health workers. The aim of this study is to know the perception of mothers about food allergy, including its pathophysiology, clinical symptoms and signs, management, and kinds of food as allergens. 


\section{Methods}

This cross sectional study was performed from February to April 1996 in the Growth and Development Clinic Sardjito General Hospital Jogja Indonesia. Subjects of the study were mothers who brought their babies to this clinic. An informed consent was obtained from the subjects. Data were collected with interviews using a standardized questionnaire done by dietitians. Chi square test was performed to differentiate proportion of two variables. A value of $p<0.05$ is considered as a significant statistical difference.

\section{Results}

There were 114 respondents who signed the informed consent. The subject characteristics were showed in Table 1 . Table 1 showed that majority of subjects aged between 20 to 30 years $(64.0 \%)$, highly educated $(47.4 \%)$, housewives $(52.7 \%)$, had one child $(57.9 \%)$. The majority of their spouses aged between 30-40 years (56.2\%), highly educated $(57.8 \%)$, work as private employees $(40.4 \%)$. The subjects came from high socioeconomic status.

\section{Mothers' perceptions about food allergy}

At the first step, the mothers' perceptions about 11 items of food allergy were collected (Table 2). Data showed that there were some misleading about food allergy, such as food allergy can not be inherited $(48.2 \%)$, egg causes furuncle $(54.3 \%)$, breast milk causes atopic eczema (46.5\%), food allergy does not relate to respiratory symptoms $(36.8 \%)$. In order to study the difference of proportion between mothers' educational level with some knowledge items, chi square tests were performed (Table 3).

There were more mothers from medium educational level who stated that 'food allergy could not be inherited' and 'antigen can be transferred via breast milk', compared to those who from high and low educational level. These proportions were significantly different ( $\mathrm{p}$ $=0.003$ and $\mathrm{p}=0.003$ ). This result may be not consistent with other studies where low educated mothers had better perception about heredity of food allergy compared to mothers from medium education level. We could not give exact explanation about this situation. Mothers with low educational level in this study may receive information from other resources rather than formal education, including health providers.
TABLE 1. CHARACTERISTICS OF THE SUBJECTS

\begin{tabular}{|c|c|c|}
\hline Variables & $\mathrm{n}$ & $\%$ \\
\hline \multicolumn{3}{|l|}{ Age } \\
\hline - $<20$ years & 4 & 3.5 \\
\hline - $20-30$ years & 73 & 64.0 \\
\hline - $\quad 31-40$ years & 35 & 30.7 \\
\hline - $\quad>40$ years & 2 & 1.8 \\
\hline \multicolumn{3}{|l|}{ Education level } \\
\hline \multirow{3}{*}{$\begin{array}{ll}\text { - } & \text { low educated } \\
\text { - } & \text { medium educated } \\
\text { - } & \text { high educated }\end{array}$} & 9 & 7.9 \\
\hline & 51 & 44.7 \\
\hline & 54 & 47.4 \\
\hline \multicolumn{3}{|l|}{ Occupation } \\
\hline - housewife & 60 & 52.7 \\
\hline - $\quad$ civil servant & 16 & 14.0 \\
\hline - teacher/lecturer & 17 & 14.9 \\
\hline - $\quad$ private employee & 14 & 12.3 \\
\hline - $\quad$ business women & 3 & 2.6 \\
\hline - $\quad$ others & 4 & 3.5 \\
\hline \multicolumn{3}{|l|}{ Number of child } \\
\hline - 1 & 66 & 57.9 \\
\hline - 2 & 29 & 25.4 \\
\hline - 3 & 14 & 12.3 \\
\hline - $\quad>3$ & 5 & 4.4 \\
\hline \multicolumn{3}{|l|}{ Spouse's age } \\
\hline - 20-30 years & 42 & 36.8 \\
\hline - $\quad 31-40$ years & 64 & 56.2 \\
\hline - $\quad>40$ years & 8 & 7.0 \\
\hline \multicolumn{3}{|l|}{ Spouse's education level } \\
\hline - low educated & 7 & 6.2 \\
\hline - $\quad$ medium educated & 41 & 36.0 \\
\hline - high educated & 66 & 57.8 \\
\hline \multicolumn{3}{|l|}{ Spouse's occupation } \\
\hline - $\quad$ civil servant & 35 & 30.7 \\
\hline - $\quad$ private employee & 46 & 40.4 \\
\hline - $\quad$ teacher/lecturer & 17 & 14.9 \\
\hline - businessmen & 16 & 14.0 \\
\hline
\end{tabular}

Skin manifestations of food allergy were most popular among medium educated mothers compared to high and low educated mothers $(\mathrm{p}=0.001)$. Again, explanation about this result was not available.

\section{Foods as causes of food allergy}

Figure 1 and Figure 2 showed that animal proteins were more popular than plant proteins that cause food allergy. From group of animal proteins, egg, shrimp, fish, shellfish and cow milk were the most popular kinds of foods that cause food allergy among children compared to other foods such as chicken, breast milk, beef, cheese and butter. Whereas, peanut, soy, banana, rice and vegetables were recognized as major causes of food allergy among plant foods. 
TABLE 2. MOTHERS' PERCEPTION ABOUT FOOD ALLERGY

\begin{tabular}{|c|c|c|c|c|c|c|}
\hline \multirow[t]{2}{*}{ Perception } & \multicolumn{2}{|l|}{ agree } & \multicolumn{2}{|c|}{ do not know } & \multicolumn{2}{|c|}{ do not agree } \\
\hline & & $\%$ & $\mathrm{n}$ & $\%$ & $\mathrm{n}$ & $\%$ \\
\hline Food allergy Is inherited & 49 & 42.9 & 10 & 8.8 & 55 & 48.2 \\
\hline Food allergy is a communicable diseases & 18 & 15.8 & 4 & 3.5 & 92 & 80.7 \\
\hline Food allergy may affect children & 92 & 80.7 & 6 & 5.3 & 16 & 14.1 \\
\hline Egg causes furuncle & 62 & 54.3 & 16 & 14.0 & 36 & 31.6 \\
\hline Breast milk causes infantile eczema & 53 & 46.5 & 12 & 10.5 & 49 & 43.0 \\
\hline Antigen can be transferred via breast milk & 51 & 44.8 & 13 & 11.4 & 50 & 43.8 \\
\hline Food allergy causes skin symptoms or signs & 88 & 77.2 & 11 & 9.6 & 15 & 13.1 \\
\hline Food allergy causes digestive symptom or signs & 64 & 56.1 & 24 & 21.1 & 26 & 22.8 \\
\hline $\begin{array}{l}\text { Food allergy causes respiratory symptoms or signs } \\
\text { Food aversion prevents the manifestation }\end{array}$ & 43 & 37.7 & 29 & 25.4 & 42 & 36.8 \\
\hline of food allergy & 72 & 63.1 & 13 & 11.4 & 29 & 25.4 \\
\hline Special milk can be used in cow milk allergy & 86 & 75.4 & 14 & 12.3 & 14 & 12.3 \\
\hline
\end{tabular}

TABLE 3. THE PROPORTION OF MOTHERS' PERCEPTION ACCORDING TO THEIR EDUCATIONAL LEVELS*

\begin{tabular}{llll}
\hline Perceptions & $\mathrm{X}^{2}$ & $\mathrm{df}$ & $\mathrm{p}$ values \\
\hline & & & \\
Food allergy is inherited & 12.402 & 4 & $0.02^{* *}$ \\
Egg causes furuncle & 6.474 & 4 & 0.17 \\
Breast milk causes infantile atopic eczema & 5.429 & 4 & 0.25 \\
Food allergy causes skin symptoms and signs & 17.863 & 4 & $0.001^{* * *}$ \\
Food allergy causes digestive symptoms and signs & 5.349 & 4 & 0.25 \\
Food allergy causes respiratory symptoms and signs & 2.001 & 4 & 0.73 \\
Antigen can be transferred via breast milk & 11.048 & 4 & $0.03^{* *}$ \\
& & & \\
\hline
\end{tabular}

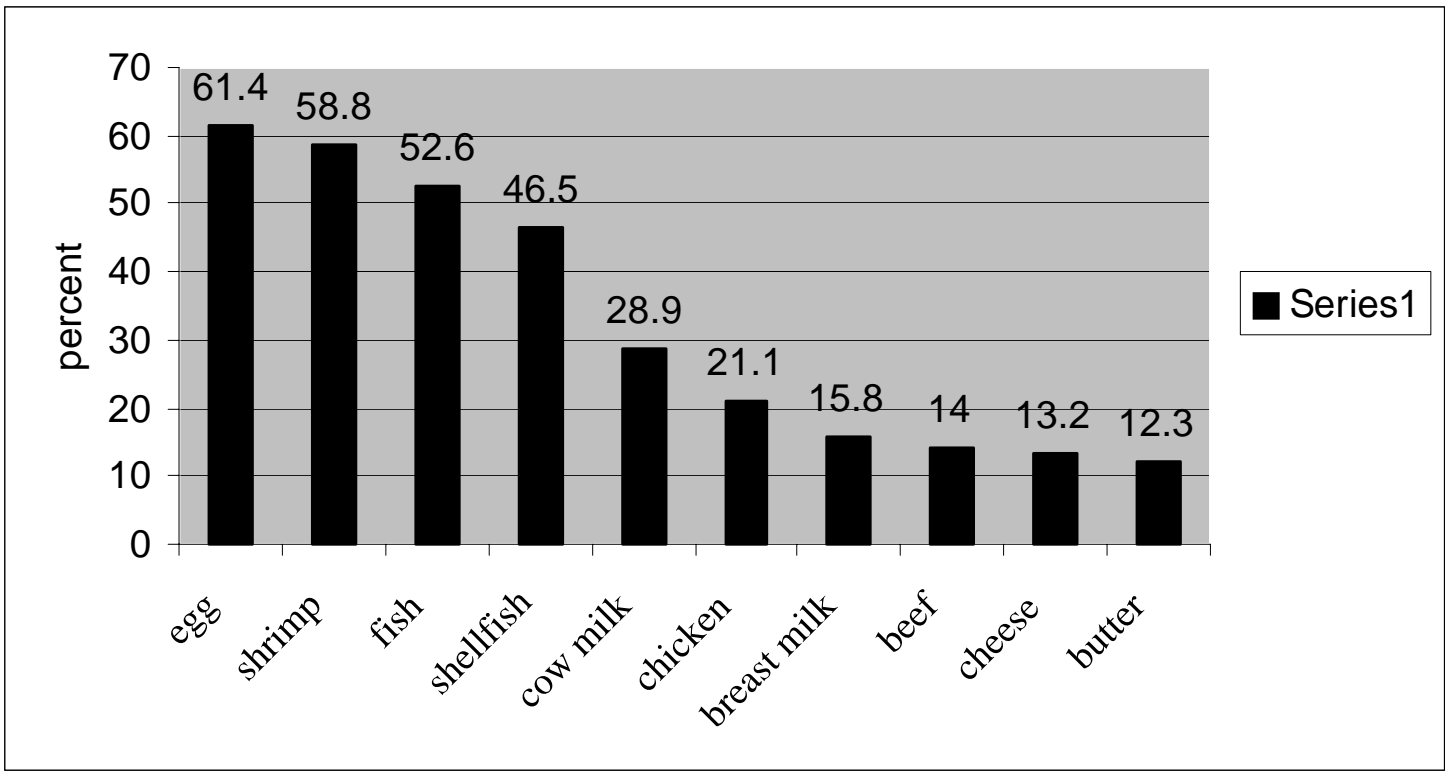

Figure 1. Animal foods as the causes of food allergy 


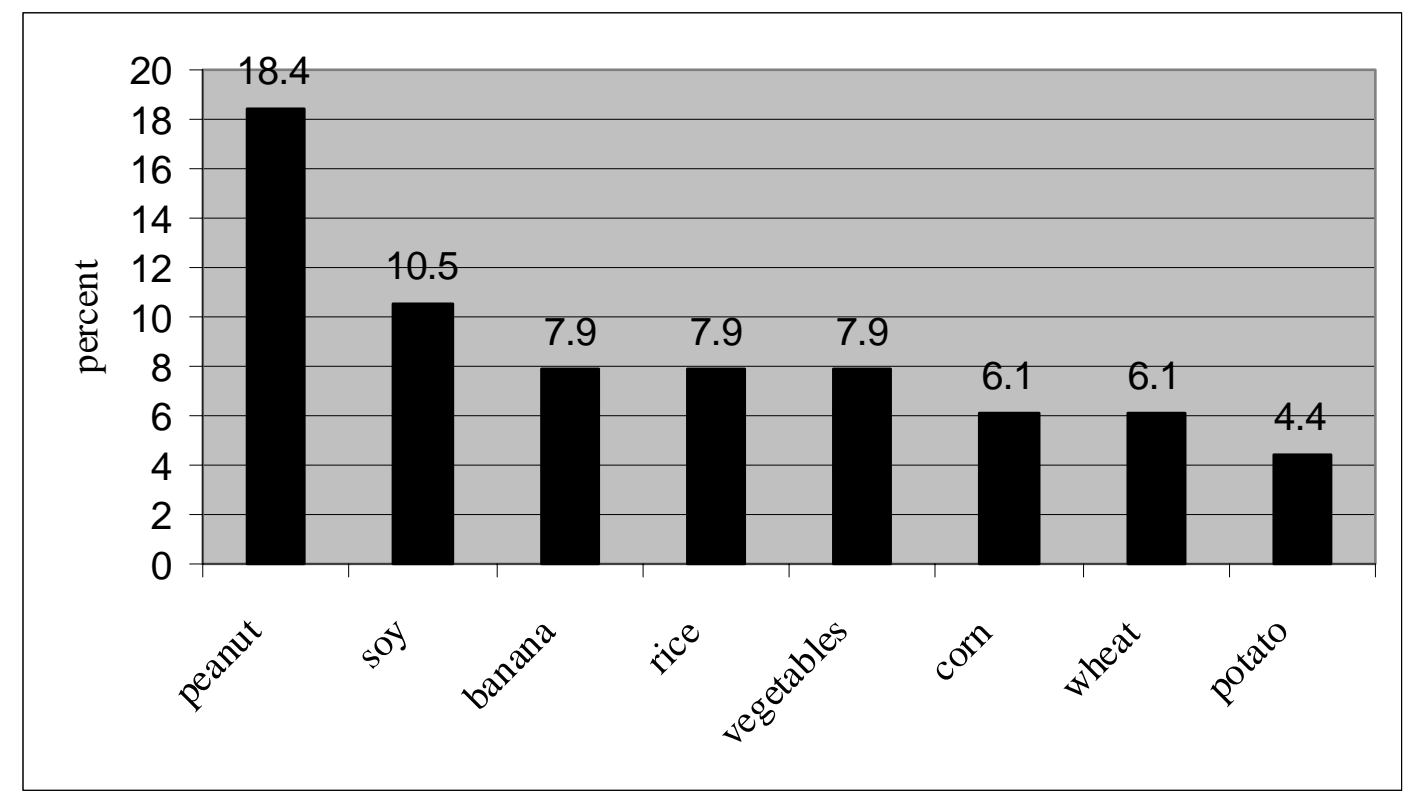

Figure 2. Plant foods as the causes of food allergy

\section{Discussion}

Among mostly high-educated mothers who visited Sardjito Hospital, food allergy is still 'a strange thing'. From these results we could discus some important issues. Firstly, although this study did not distinguish between perception about food allergy and food intolerance, that might be some confusion among mothers about this situation. In the recent years, diagnoses of 'food allergy' and 'food intolerance' become popular without the necessary differentiation provided by precise definitions ${ }^{2}$. Secondly, educational level does not prove any differentiation regarding the perception about food allergy. Health professionals who meet allergic children should give proper information to their parents about food allergy without considering educational level guarantee. In developed countries parents' perception can be used to assess the prevalence of food allergy and food intolerance in community. A study done in England and Scotland found that $3 \%$ of children were perceived as being food intolerance ${ }^{3}$, whereas a similar study done in Holland showed a prevalence of 'probable' food intolerance was 3.8\%. ${ }^{4}$ Thirdly, although the perception about 'breast milk causes atopic eczema' is likely has minimal effect on lactation practices according to observation in clinics and communities, this study is not designed to prove this problem. Most of mothers think that breast milk pours on baby's cheeks during breast-feeding is the cause of atopic eczema. Fourthly, variety of symptoms stated by mothers correlate with the clinical symptoms reported in most of studies. Skin reaction is the most popular symptom, followed by gastrointestinal symptoms and respiratory symptoms. ${ }^{5}$ A study done in Jogja reported, that most of children with food allergy experienced skin and respiratory symptoms. ${ }^{6}$ Fifthly, perception of mothers about types of food are commonly similar with other study. Based on challenge tests in 63 of 113 patients with atopic dermatitis, prevalence of egg allergy is the highest followed peanuts. ${ }^{7}$ This study demonstrated that egg was the most popular food from animal that causes food allergy, whereas peanut was the most popular food that causes food allergy from non animal products. Another study done in Jogja showed that from 9 children with food allergy, egg was the cause of food allergy in 6 of them.

The impact of food avoidance in children to their nutritional status is interestingly observed, especially 
in rural areas, where egg is inexpensive source of protein from animal product. Perception of mothers about food allergy in rural areas might not be different from this study, but further researches which are exploring the perception and practices of parents regarding food allergy in their children, are recommended.

Among medium to highly educated mothers there is still wrong perception about food allergy. The relationship between the wrong perception and child's nutritional status and growth is not evaluated in this study. Because of egg is important and inexpensive source of protein for children especially in rural areas, a further research focusing in this problem is recommended.

\section{Acknowledgments}

The author thanks Ms Tri Sumasti Rahayuningsih and Ibnu Dwi Saptono (dietitians of Nutrition Department Sardjito Hospital Jogja) for their assistance in data collection.

\section{References}

1. Chandra RK, Gill B, Kumari S. Food allergy and atopic disease: pathogenesis, diagnosis, prediction of high risk, and prevention. Ann Allergy 1993; 71: 495-502.

2. Esteban MM. Adverse food reactions in childhood: Concept, importance, and present problems.J Pediatr 1992; 121: S1-S3.

3. Rona RJ, Chinn S. Parents' perceptions of food intolerance in primary school children. BMJ 1987; 294: 863-6.

4. Aardoom HA, Hirasing RA, Rona RJ, Sanavro FL, van den Heuvel EW, Leeuwenburg J. Food intolerance (food hypersensitivity) and chronic complaints in children: the parents' perception. EurJPediatr 1997; 156: 110-2.

5. Nieto A. Clinical methods for diagnosis of food allergy. Businco L, Oehling B, Renner B, Morán J, editors. Presented at the International Symposium Food Allergy in Infancy, Palma de Mallorca, Spain, December 3-4, 1991.

6. Elberink R, Hennepe I, Prawirohartono EP, Douwes AC. Food allergy in Indonesian Children. Thesis. Amsterdam: Free University, 1995.

7. Sampson HA, McCaskill CC. Food hypersensitivity and atopic dermatitis: Evaluation of 113 patients. J Pediatr 1985; 107: 669-75. 